\title{
A rare case of arteriovenous malformation following hysterectomy in a case of choriocarcinoma
}

\author{
Suchitra $\mathbf{R}^{1 *}$, Manjunath $\mathbf{P}^{2}$, Shameem Taj ${ }^{1}$, Radhika Kalla ${ }^{1}$
}

\begin{abstract}
${ }^{1}$ Department of Gyneac-oncology, Mazumdar Cancer Centre, Narayana Health, Bangalore, Karnataka, India ${ }^{2}$ Department of Vascular and Interventional Radiology, Mazumdar Cancer Centre, Narayana Health, Bangalore, Karnataka, India
\end{abstract}

Received: 02 July 2015

Revised: 28 August 2015

Accepted: 29 August 2015

\author{
*Correspondence: \\ Dr. Suchitra R, \\ E-mail: docsuchitra100@gmail.com
}

Copyright: (C) the author(s), publisher and licensee Medip Academy. This is an open-access article distributed under the terms of the Creative Commons Attribution Non-Commercial License, which permits unrestricted non-commercial use, distribution, and reproduction in any medium, provided the original work is properly cited.

\begin{abstract}
A uterine arteriovenous malformation (AVM) is a rare cause of uterine bleeding. It may have varied presentations ranging from being completely asymptomatic; to features of congestive heart failure, to vaginal bleeding which may at times life be threatening. Clinical findings in such cases are often un-reliable; requiring a high index of suspicion to make the diagnosis. We report a case of a 46-year-old lady who presented with heavy vaginal bleeding. She has undergone hysterectomy with a histopathology of choriocarcinoma one and half months back. She has received chemotherapy and 8 fractions of radiotherapy for the same. AVM was diagnosed following a CT angiogram and was managed by embolization. We also discuss in brief about this uncommon but serious condition which the radiologist/gynaecologist may encounter in their practice. AV Malformation is a rare but potentially life-threatening cause of vaginal bleeding which must be kept in the differential diagnosis of sudden and massive vaginal bleeding. It requires a high index of clinical suspicion. Despite its rarity, early recognition of an AVM is imperative to enable timely diagnosis and intervention.
\end{abstract}

Keywords: AVM, Choriocarcinoma, CT angiogram, Embolisation

\section{INTRODUCTION}

Arteriovenous malformations of the uterus are uncommon entities and should be considered in patients who present with unexplained profuse genital bleeding. It can result in a life-threatening medical emergency with unexpected sudden and massive vaginal bleeding. This entity is generally associated with presence of molar disease, choriocarcinoma and uterine surgery, but may be congenitally acquired.

Choriocarcinoma is a vascular tumor with high incidence of metastases, the most common being lungs, vagina, brain and liver and rarely gastrointestinal tract, kidney, spleen, genital tract and the lymph nodes.

We report a case of acquired AV malformations in the vagina following hysterectomy for choriocarcinoma.

\section{CASE REPORT}

A 46 year old female came with the complaints of heavy vaginal bleeding to the causality. She gives a history of hysterectomy one and half months back for DUB. 
Histopathology reported as choriocarcinoma. She took one cycle of chemotherapy (EMACO) and 8 \# of radiotherapy for the same. She received two units of blood in the causality and was stabilised.

Her $\beta$-hCG values on arrival were normal $(<2 \mathrm{mIU} / \mathrm{ml})$. PET CT showed no increased uptake anywhere indicating no residual or recurrent disease. An examination under anaesthesia was performed which showed a $3 \times 4 \mathrm{~cm}$ lesion on the right lateral aspect of the vagina. Vault was healthy and the lesion was 3 to $4 \mathrm{~cm}$ away from the vault. Biopsy was attempted but abandoned as she started bleeding heavily. Sutures were taken and haemostasis secured. She had another bout of heavy bleeding three days later when a CT angiogram was done .Features- CT scan showed $3.3 \times 2.6 \times 4.7 \mathrm{~cm}$ lesion in the left lateral wall of vagina. On post contrast study, tortuous vessels were seen at the periphery of the lesion. A prominent branch is seen arising from anterior division of left internal iliac artery and supplying the mass opacification lesion. CT angiogram demonstrated an early venous pacification in the arterial phase and the same is appreciated in the delayed phase also. However there was no significant extra vacation. The rest of the abdominal examination was normal.

Percutaneous transluminal catheter angiogram revealed AVM from the left internal iliac artery. Significant hypertrophied vessels arising from the anterior branch demonstrating the nidus and early washout of the venous phase. However there is no abnormal venous demonstration of fistulous communication at the left pelvic region. Superselectively the nidus is accessed and successful embolization done for all the feeding vessels using Histoacryl glue and PVA particles. Post embolisation angiogram done after 15 minutes showed no residual extravasation or pooling of the hypertrophied vessels. The nidus was successfully embolized without any significant collaterals in the pelvic region.
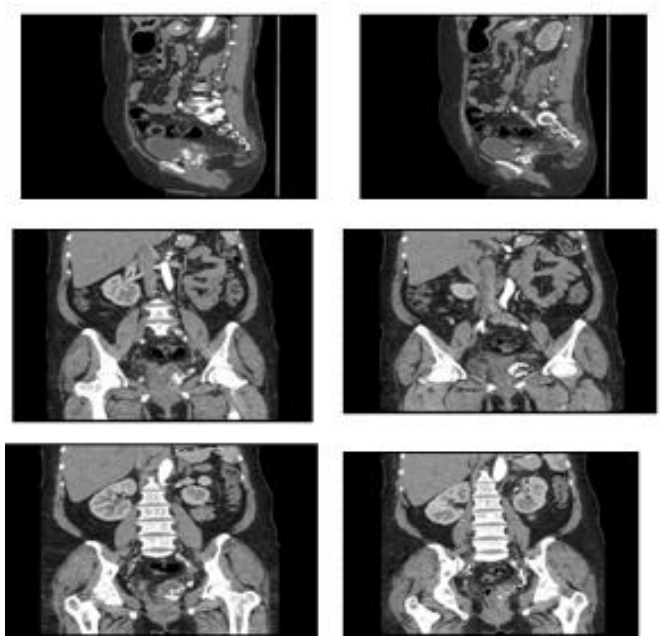

Figure 1: Pre embolization CT contrast images showing the coronal and saggital views of pelvis with hypertrophied vessels.

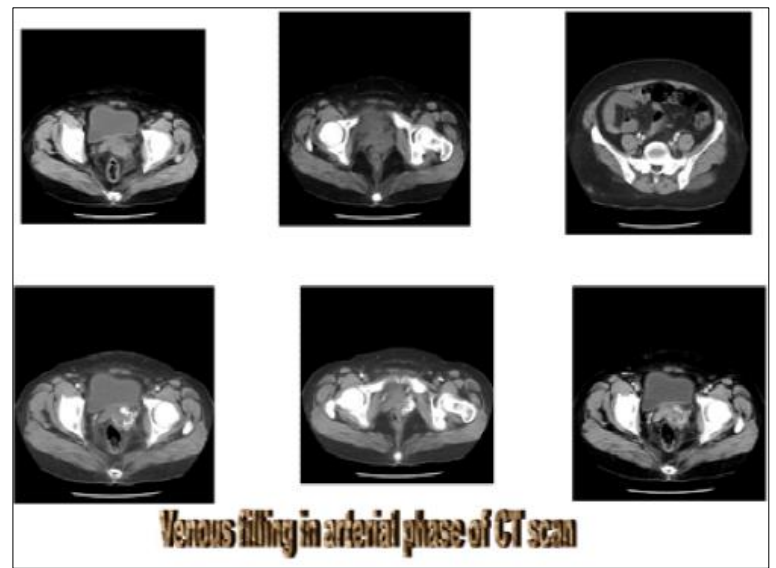

Figure 2: Pre embolization axial views of pelvis with hypertrophied vessels.

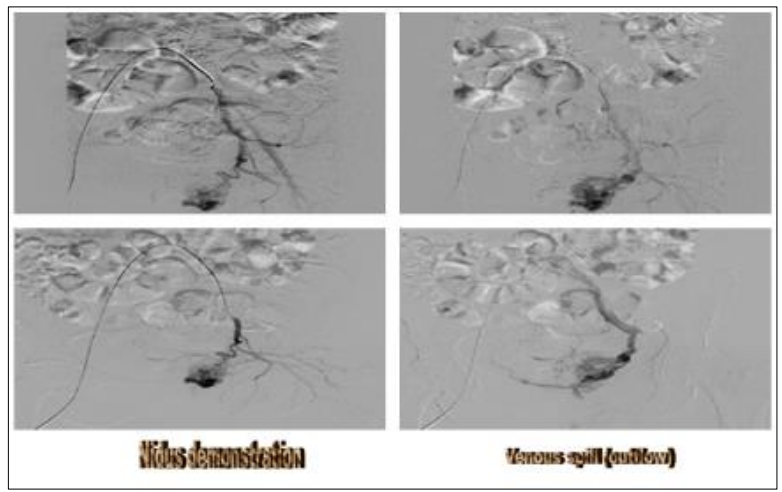

Figure 3: Showing arterial and venous filling following contrast. There was a nidus formation noted indicating an AVM. There was no fistula seen.

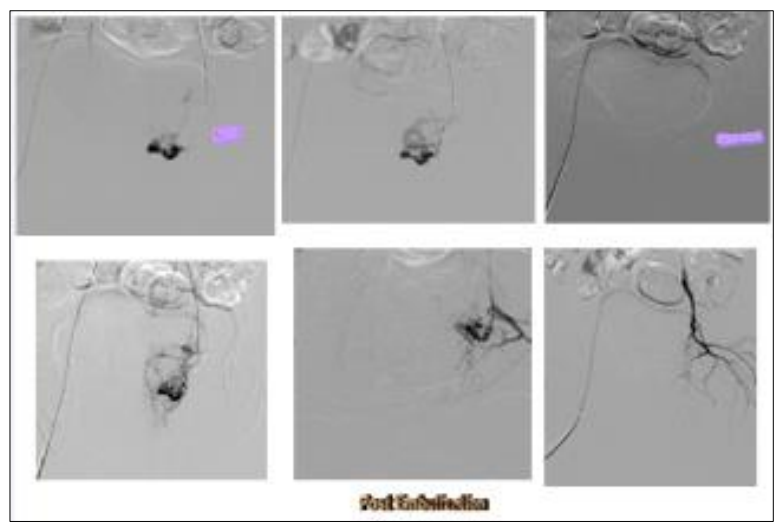

Figure 4: Post embolization images showing no extravasation and hypertrophy of vessels indicating successful embolization of the AVM.

\section{DISCUSSION}

The first case of AVM was reported in 1926 by Dubreuil and Loubat. ${ }^{1}$ It consists of proliferation of arterial and venous channels with fistula formation and admixture of small capillary like channels. In many cases, distinction between artery and vein becomes blurred due to 
secondary intimal thickening in the veins as a result of increased intraluminal pressure.

Arteriovenous malformations of the uterus are rare congenital anomalies whose true incidence is unknown. Their incidence has been roughly estimated to be around $4.5 \% .^{2}$

These may be either congenital or acquired. Congenital malformations are a result of abnormal embryologic angiogenesis leading to the formation of multiple abnormal connections between arteries and veins. ${ }^{3}$ Acquired AVMs (also known as traumatic AVMs) are formed due to multiple small fistulae between arteries and veins and occur as a result of previous uterine instrumentation, gestational trophoblastic disease, choriocarcinoma, endometrial carcinoma, cervical cancer, infection or uterine surgery and trauma.,

Imaging features in both forms are similar and patient history is helpful in distinguishing the two. They most commonly affect women in the reproductive age group. ${ }^{6}$ AVMs may occur in isolation or as a part of a syndrome, and may be congenital or acquired. In general, vascular lesions may be classified based on the main channel type, that is, arterial, venous, capillary, lymphatic, or mixed. They can be further subdivided based on flow characteristics into slow-flow or fast-flow lesions. Slowflow lesions include venous, capillary, and lymphatic vascular malformations, and fast-flow lesions include arterial, arteriovenous, and arteriovenous fistula vascular malformations. The majorities of AVMs of the female genital tract are asymptomatic and found incidentally; however, when symptomatic, they can cause profuse bleeding and hemodynamic changes, both of which are related to the size of the $\mathrm{AVM}^{7}$

Imaging assessment of uterine AVMs, especially their vascular anatomy, is very important during the planning stages before embolization, such as Doppler ultrasonography, CT, and MRI. ${ }^{8-11}$ Ultrasound is the initial imaging of choice. Gray scale sonography shows multiple heterogeneously hypoechoic or anechoic tortuous spaces. Colour Doppler ultrasonography reveals a meshwork of vessels producing a "color mosaic" pattern with high- and low-velocity flows in different directions. ${ }^{11}$ Spectral Doppler shows low-resistance and high-peak systolic velocities with continuous high flow throughout the systole and diastole. ${ }^{11}$ MRI provides accurate anatomical details as well as relation with surrounding structures. However, it has obvious disadvantages, i.e. limited availability and being expensive. Both of these disadvantages are a major constraint in its wide-spread use, especially in the developing countries. Angiography is the gold standard in the diagnostics ${ }^{11,12}$ of AVM, depicting complex vascular connections supplied by hypertrophied feeding arteries and early drainage through enlarged, tortuous and hypertrophic veins. ${ }^{12}$ It has an added advantage of embolisation in the same setting. However, it is invasive, requires expertise, and the Cath lab is available only at few places.

In this patient, given her pattern of delayed, non-cyclic and heavy vaginal bleeding, we remained suspicious about a vascular lesion. We postulate that the triggering event for severe vaginal bleeding in our patient could have been the effect of radiotherapy on a previous metastatic lesion. Finally, the possibility that the AVM was merely an incidental finding cannot be ruled out confidently.

We accessed the right common femoral artery in this patient and a 5-Fr introducing angiographic sheath (Terumo Corporation, Tokyo, Japan) was placed. A 5-Fr Cobra catheter (Cook, Bloomington, IN, USA) was used to perform nonselective angiograms of the internal iliac arteries. A 5 Fr RUC catheter (Cook, Bloomington, USA) was used to superselectively catheterise the hypertrophied vessels of the left internal iliac arteries. The feeding vessels were then embolised using Histoacryl glue.

Haemodynamically unstable and anaemic patients should be offered angiography and embolisation. It is a very good treatment option with a high success rate, fewer complications. In patients with severe vaginal bleeding, especially in the presence of hemodynamic instability, it is of vital importance to start aggressive resuscitation with fluids and blood products. Temporary emergent measures like tamponade with a Foley catheter may be performed to manage life-threatening haemorrhage. ${ }^{2}$ In stable women, expectant management, surgical removal of an AVM, laparoscopic bipolar coagulation or ligaton of the uterine blood vessels or as in this case internal iliac vessel can be done. Recent reports have described successful treatment of arterial embolization with different materials used singly or in combination such as autologous blood clot, gelfoam, microfibrillar collagen, polyvinyl alcohol, isobutyl cyanoacrylate and steel coil spring occluders. ${ }^{13}$

\section{CONCLUSION}

AV malformation is a rare but potentially lifethreatening. So while dealing with a case of refractory type of vaginal bleeding one should always consider the possibility of uterine AVM. Since the lesion was significantly away from the vault, the AVM could not be attributed to the surgery. Probably it could have been the effect of radiotherapy on a previous metastatic lesion. Despite its rarity, early recognition of an AVM is imperative to enable timely diagnosis and intervention. ${ }^{9}$

Funding: No funding sources

Conflict of interest: None declared

Ethical approval: Not required

\section{REFERENCES}

1. Dubreuil G, Loubat E. Aneurysme crisoide de 1 ? Uterus Ann Anat Pathol. 1926;3:697-718. 
2. O'Brien P, Neyastani A, Buckley AR, Chang SD, Legiehn GM. Uterine arteriovenous malformations: from diagnosis to treatment. J Ultrasound Med. 2006;25:1387-92.

3. Selby ST, Haughey M. Uterine arteriovenous malformation with sudden heavy vaginal hemmorhage. West J Emerg Med. 2013;14:411-14.

4. Hoffman MK, Meilstrup JW, Shackelford DP, Kaminski PF. Arteriovenous malformations of the uterus: an uncommon cause of vaginal bleeding. Obstet Gynecol Surv. 1997;52:736-40.

5. Fleming $\mathrm{H}$, Ostör AG, Pickel H, Fortune DW. Arteriovenous malformations of the uterus. Obstet Gynecol. 1989;73:209-14.

6. Goldrath MH. Uterine tamponade for the control of acute uterine bleeding. Am J Obstet Gynecol. 1983; 147:869-72.

7. Gary P. Siskin. Application of pelvic embolization beyond uterine fibroids in interventional radiology in women's health. Thieme. 2011 Jan;8:85-90.

8. Flynn MK, Levine D. The noninvasive diagnosis and management of a uterine arteriovenous malformation. Obstet Gynecol. 1996;88(4 Pt 2):6502.
9. Cura M, Martinez N, Cura A, Dalsaso TJ, Elmerhi F. Arteriovenous malformations of the uterus. Acta Radiol. 2009;50:823-9.

10. Timmerman D, Van den Bosch T, Peeraer K, Debrouwere E, Van Schoubroeck D, Stockx L, et al. Vascular malformations in the uterus: ultrasonographic diagnosis and conservative management. Eur J Obstet Gynecol Reprod Biol. 2000;92:171-8.

11. O'Brien P, Neyastani A, Buckley AR, Chang SD, Legiehn GM. Uterine arteriovenous malformations: from diagnosis to treatment. J Ultrasound Med. 2006;25:1387-92.

12. Brown JV 3rd, Asrat T, Epstein HD, Oglevie S, Goldstein BH. Contemporary diagnosis and management of a uterine arteriovenous malformation. Obstet Gynecol. 2008;112(2 Pt 2):467-70.

13. Fleming $H$, Ostor AQ, Pickel $H$, Forune DW. Artiovenous malformations of the ulerus. Obstet Gyneccol. 1989;73(2):209-14.

Cite this article as: Suchitra R, Manjunath $\mathrm{P}$, Taj S, Kalla R. A rare case of arteriovenous malformation following hysterectomy in a case of choriocarcinoma. Int J Reprod Contracept Obstet Gynecol 2015;4:1561-4. 